\title{
Rodent Host Abundance and Climate Variability as Predictors of Tickborne Disease Risk 1 Year in Advance
}

\section{Emil Tkadlec, Tomáš Václavík, Pavel Široký}

Using long-term data on incidences of Lyme disease and tickborne encephalitis, we showed that the dynamics of both diseases in central Europe are predictable from rodent host densities and climate indices. Our approach offers a simple and effective tool to predict a tickborne disease risk 1 year in advance.

$\mathrm{I}^{\mathrm{n}}$ $\mathrm{n}$ Europe, the generalist tick Ixodes ricinus is the principal vector transmitting tickborne pathogens to humans. It has 3 blood-feeding stages, depending on small rodents, such as voles and mice, as the chief reservoir hosts for larval ticks (1). The development from larva to nymph is a key aspect in pathogen transmission because the exposure to pathogens is most likely to happen at this stage and therefore directly influences the density of infected nymphs (2). Vole population densities change dramatically over time in intervals of 3-5 years (3), known as population cycles (4). As a result, the chances for questing larvae to encounter a host are expected to vary considerably over time, along with vole population numbers. Investigations of direct relationships between abundance of ticks, disease incidence, and host populations are rare, usually targeting large mammals that provide a blood meal for female adult ticks (5). Little is known about the effect of rodent population dynamics on abundance of nymphal ticks ( 6 ), and studies of the direct effects on disease risk are even rarer $(7,8)$.

We studied interannual variation in incidences of 2 tickborne diseases (TBDs), Lyme disease (LD) and tick-borne encephalitis (TBE). We aimed to determine if, as suggested by a previous work in North America (8), disease risk is related to rodent abundance during

Author affiliations: Palacký University Olomouc, Olomouc, Czech Republic (E. Tkadlec, T. Václavík); Institute of Vertebrate Biology, Brno, Czech Republic (E. Tkadlec), UFZ-Helmholtz Centre for Environmental Research, Leipzig, Germany (T. Václavík); University of Veterinary and Pharmaceutical Sciences Brno, Brno (P. Široký); Central European Institute of Technology, Brno (P. Široký)

DOI: https://doi.org/10.3201/eid2509.190684 the previous year. We also tested the hypothesis that population outbreaks in the common vole (Microtus arvalis), along with favorable weather conditions, increase survival of larval ticks and the abundance of nymphal ticks in the following year, thereby resulting in higher disease incidence.

\section{The Study}

We analyzed periods of 17-18 years to assess TBD incidences in 7 countries in central Europe (Figure 1; Appendix Figure 1, https://wwwnc.cdc.gov/EID/article/25/9/190684-App1.pdf). First, we computed the cross-correlations between disease incidences, vole densities from the Czech Republic, and climate variables to examine the degree of synchrony among their dynamics. Second, we applied autoregressive linear models of order $0-2$ to test whether the predictive abilities of vole abundance in year $t-1$ are supported by data (Appendix). Finally, we tested the influence of climate indices that are known to affect tick ecology (9). We used Akaike information criterion for small samples to compare models. The effect included in the model was considered to be strongly supported by data if the model Akaike information criterion was reduced by $>2$. We obtained data on annual TBD incidences, vole abundance (autumn counts of burrow entrances per hectare), and climate variability (North Atlantic oscillation [NAO] indices) from public databases (Appendix).

LD incidences for 3 countries in central Europe fluctuated over time (Figure 2). Cross-correlation analysis revealed strong positive correlations between incidences in the Czech Republic in year $t$ and vole densities in $t-1$ and negative correlations between the annual NAO index in $t-1$ (Appendix Figures 2-4). By fitting autoregressive linear models, we found strong evidence that vole abundance in year $t-1$ and the annual NAO index in $t-1$ are key to predicting LD incidences during year $t$ in the Czech Republic (Table 1); the final model predicted observed incidence with reasonable accuracy (Appendix Figure 5). LD incidence increased with vole densities and decreased with the annual NAO index (Appendix Figure 6).

TBE incidence from 7 countries fluctuated greatly from year to year (Figure 2). Cross-correlations showed that TBE incidence was strongly positively correlated with 


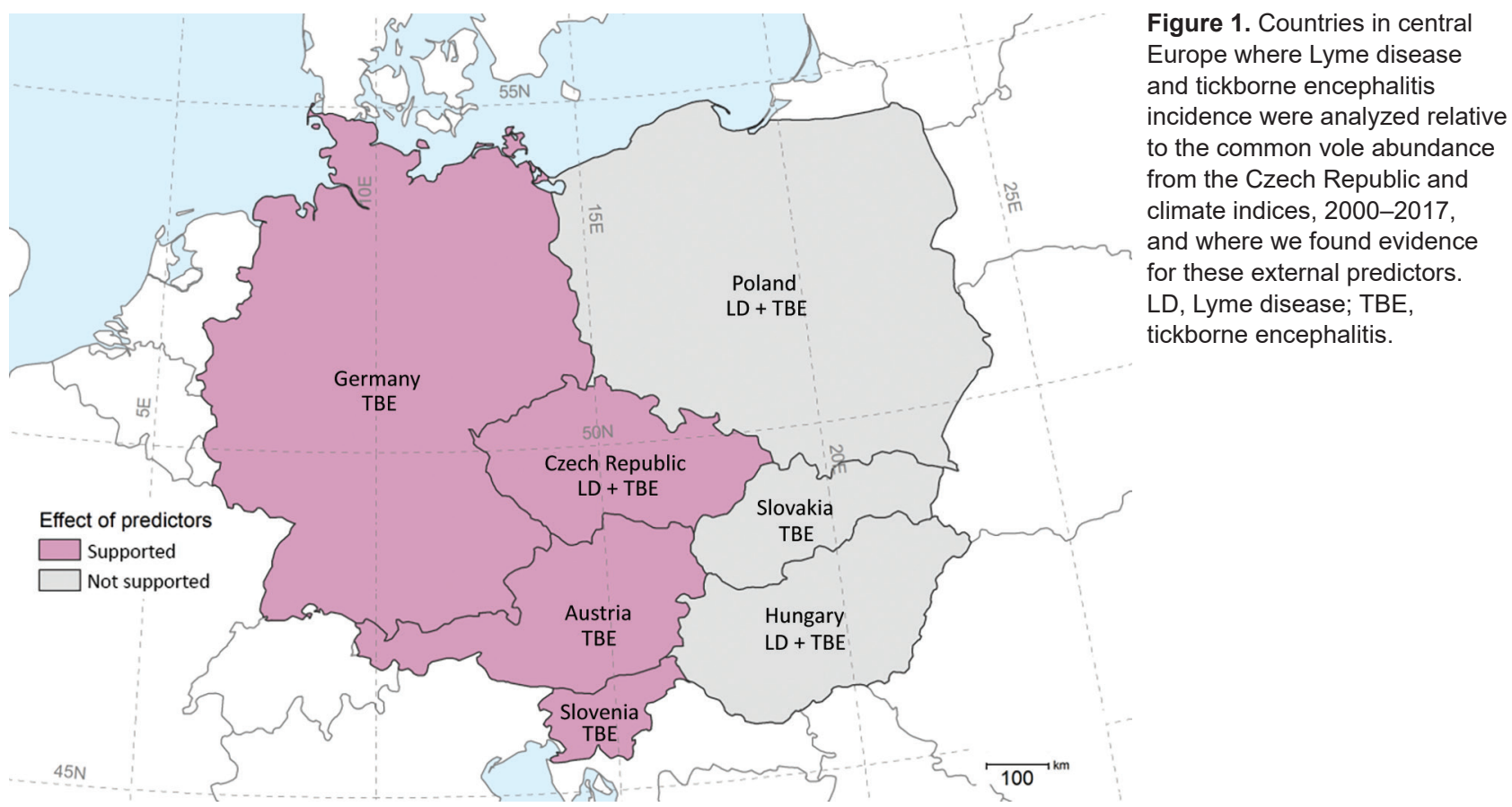

vole density with a lag of 1 year for the Czech Republic, Germany, and Slovenia (Appendix Figure 7). A lag of 1 year for the effect of the annual NAO index was negatively correlated with TBE incidence in the Czech Republic and Germany, whereas a 2-year lag was positively correlated with TBE incidence in Germany and Austria (Appendix Figure 8). Autoregressive linear models showed that including vole abundance from year $t-1$ improved fit for the Czech Republic, Germany, and Slovenia (Table 2). Adding the effect of the annual NAO index in $t-1$ to the model improved the fit in the Czech Republic and Germany. The effect of the annual NAO index in $t-2$ produced better predictive power for Austria. As a result, the best models for TBE incidence in all 4 countries (Czech Republic, Germany, Slovenia, and Austria) included both host abundance and climate effect. Incidence of both diseases fluctuated over time in close synchrony, as revealed for the Czech Republic (correlation coefficient 0.71) and Poland (correlation coefficient 0.70) (Appendix Figure 9).

\section{Conclusions}

For 4 of the 7 countries in Europe we studied, our results show support for the hypothesis that incidence of 2 TBDs should lag 1 year behind the rodent host density because of the beneficial effect on survival of I. ricinus larvae (10). Our results agree with evidence from North America that the number of I. scapularis nymphs can be predicted by small rodent density from the preceding year $(7,8)$. In addition, acorn abundance was demonstrated to predict the nymph densities equally well 2 years ahead $(7,8)$. Hence, results from North America indicated a complete causal mechanism for variation in LD incidences over time, starting with abundant acorns in year $t-2$, which increased the population of rodents in year $t-1$. High rodent density then led to the increased number of nymphs in year $t$, resulting in a greater disease incidence in humans. Our data support this mechanism and suggest that the LD system in North America based on I. scapularis and that in Europe based on I. ricinus might be functionally quite similar, differing primarily in the species involved, and that this mechanism also applies to other tickborne diseases, such as TBE.

Unlike bank voles (Myodes glareolus) and Apodemus mice (2), the common vole occupying open farmland habitats has never been regarded as the chief host for Ixodes larvae in central Europe, though it is well-known as a competent host for pathogens and larval ticks $(11,12)$. We suggest 2 explanations for the role of this rodent in disease transmission. First, common voles can be encountered frequently in forests or wetlands in peak years (13), when their densities often exceed 2,000 voles/hectare. Thus, the common vole can act as an amplifying host and contribute substantially to the whole population of suitable hosts for larval ticks. The voles' irruptive population dynamics can readily explain the upsurge in TBE disease prevalence observed in the Czech Republic in 2006, which occurred after a massive population outbreak of voles during 2004-2005 (14). Second, population fluctuations of most rodent species are spatially synchronized across large geographic areas (15). Therefore, common vole abundance is a correlative measure for bank voles or mice. 

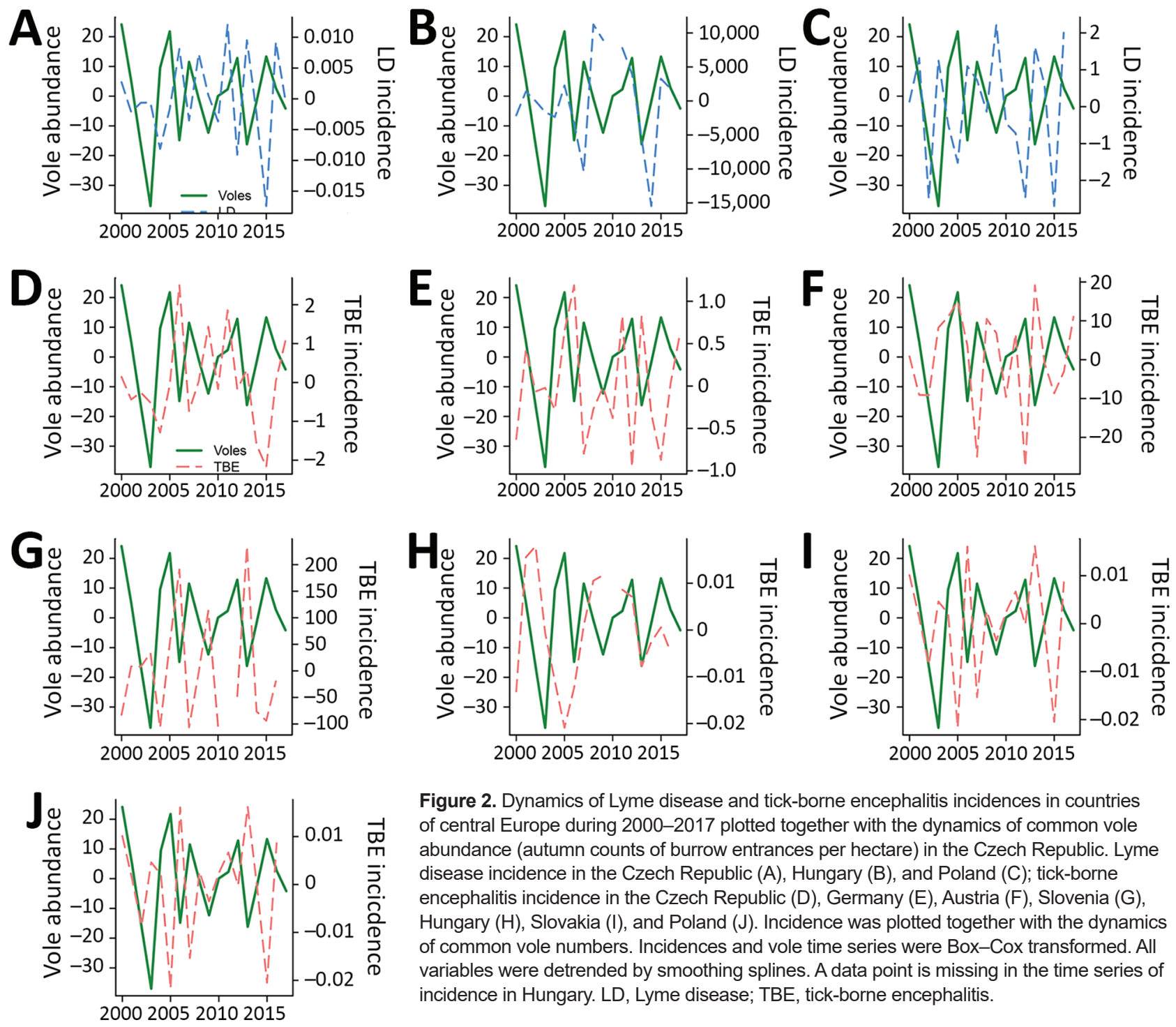

Figure 2. Dynamics of Lyme disease and tick-borne encephalitis incidences in countries of central Europe during 2000-2017 plotted together with the dynamics of common vole abundance (autumn counts of burrow entrances per hectare) in the Czech Republic. Lyme disease incidence in the Czech Republic (A), Hungary (B), and Poland (C); tick-borne encephalitis incidence in the Czech Republic (D), Germany (E), Austria (F), Slovenia (G), Hungary $(\mathrm{H})$, Slovakia $(\mathrm{I})$, and Poland $(\mathrm{J})$. Incidence was plotted together with the dynamics of common vole numbers. Incidences and vole time series were Box-Cox transformed. All variables were detrended by smoothing splines. A data point is missing in the time series of incidence in Hungary. LD, Lyme disease; TBE, tick-borne encephalitis.

Our observation that the annual NAO index in $t-1$ was able to improve model fit is in agreement with known tick ecology. A negative annual NAO index is generally associated with cold, snowy winters and moderate summers that are wetter, which can help larval ticks conserve body water and thus increase their survival to the nymphal stage (9). The positive effect of the annual NAO index in $t-2$ might signify a generally warmer year that can be related to mast seeding of trees, triggering the growth of rodent populations.

Some countries in central Europe, such as the Czech Republic, Germany, and Poland, have built programs to monitor common vole densities. These data are stored in public electronic databases and thus can be used readily for predicting TBDs, using the methods we describe.

\section{Acknowledgments}

We thank Whalen W. Dillon and Monica A. Dorning for helpful comments that greatly improved the manuscript, the National Institute of Public Health for providing us with the data on TBD incidences, and the Central Institute for Supervising and Testing in Agriculture for the data on common vole abundance.

The work was supported by the Ministry of Health of the Czech Republic (grant no. AZV 16-33934A) and Palacký University Olomouc (grant no. IGA_PrF_2019_021).

Author contributions: E.T. and T.V. conceived the ideas; E.T. analyzed the data; and E.T., T.V., and P.Š. wrote the paper. 
Table 1. Differences in AIC from the best model for Lyme disease incidences as modeled by AR linear models of order 0-2 with vole abundance and annual NAO index as external predictors, 3 countries in central Europe, 2000-2017*

\begin{tabular}{llcc}
\hline & \multicolumn{3}{c}{ Order of AR model } \\
\cline { 2 - 4 } Country and model structure & 0 & 1 & 2 \\
\hline Czech Republic & 4.1 & 3.2 & 5.0 \\
Pure AR model & 2.9 & 2.6 & 4.9 \\
Voles $_{t-1}$ & 2.8 & 3.2 & 3.7 \\
NAO annual index $t_{t-1}$ & 0.0 & 1.3 & 2.2 \\
$\quad$ Voles \\
$t-1$
\end{tabular}

Table 2. Differences in AIC from the best model for tick-borne encephalitis as modeled by AR linear models of order $0-2$ with vole abundance and annual NAO index as external predictors, 7 countries in central Europe, 2000-2017*

\begin{tabular}{|c|c|c|c|}
\hline \multirow[b]{2}{*}{ Country and model structure } & \multicolumn{3}{|c|}{ Order of AR model } \\
\hline & 0 & 1 & 2 \\
\hline \multicolumn{4}{|l|}{ Czech Republic } \\
\hline Pure AR model & 4.5 & 7.4 & 10.6 \\
\hline Voles $_{t-1}$ & 2.8 & 6.0 & 10.1 \\
\hline NAO annual index $x_{t-1}$ & 3.4 & 6.8 & 8.1 \\
\hline Voles $_{t-1}+$ NAO annual index $t_{t-1}$ & 0.0 & 3.5 & 7.5 \\
\hline \multicolumn{4}{|l|}{ Germany } \\
\hline Pure AR model & 6.0 & 7.2 & 9.2 \\
\hline Voles $_{t-1}$ & 3.6 & 6.4 & 10.1 \\
\hline NAO annual index $x_{t-1}$ & 4.8 & 7.6 & 9.7 \\
\hline Voles $_{t-1}+\mathrm{NAO}$ annual index ${ }_{t-1}$ & 0.0 & 3.8 & 7.1 \\
\hline \multicolumn{4}{|l|}{ Austria } \\
\hline Pure AR model & 5.3 & 6.5 & 9.1 \\
\hline Voles $_{t-2}$ & 5.8 & 7.3 & 9.3 \\
\hline $\mathrm{NAO}$ annual index $\mathrm{x}_{t-2}$ & 5.8 & 4.1 & 7.0 \\
\hline Voles $_{t-2}+\mathrm{NAO}$ annual index ${ }_{t-2}$ & 0.0 & 3.5 & 5.7 \\
\hline \multicolumn{4}{|l|}{ Slovenia } \\
\hline Pure AR model & 3.8 & 5.2 & 5.7 \\
\hline Voles $_{t-1}$ & 0.2 & 3.3 & 5.8 \\
\hline NAO annual index $t_{t-1}$ & 5.2 & 5.9 & 3.7 \\
\hline Voles $_{t-1}+\mathrm{NAO}$ annual index ${ }_{t-1}$ & 0.0 & 3.2 & 4.2 \\
\hline \multicolumn{4}{|l|}{ Hungary } \\
\hline Pure AR model & 0.0 & 3.2 & 4.6 \\
\hline Voles $_{t-2}$ & 0.0 & 2.1 & 5.6 \\
\hline NAO annual index $t_{t-1}$ & 3.3 & 7.2 & 6.5 \\
\hline Voles $_{t-2}+\mathrm{NAO}$ annual index ${ }_{t-1}$ & 4.1 & 7.0 & 12.0 \\
\hline \multicolumn{4}{|l|}{ Slovakia } \\
\hline Pure AR model & 1.2 & 0.0 & 3.0 \\
\hline Voles $_{t-1}$ & 3.5 & 3.4 & 7.1 \\
\hline NAO annual index $x_{t-1}$ & 3.3 & 1.3 & 3.0 \\
\hline Voles $_{t-1}+$ NAO annual index ${ }_{t-1}$ & 6.1 & 5.4 & 8.1 \\
\hline \multicolumn{4}{|l|}{ Poland } \\
\hline Pure AR model & 0.0 & 1.7 & 2.0 \\
\hline Voles $_{t-1}$ & 2.8 & 4.2 & 5.8 \\
\hline NAO annual index $x_{t-2}$ & 2.3 & 4.2 & 6.3 \\
\hline Voles $_{t-1}+$ NAO annual index $t_{t-2}$ & 5.2 & 6.7 & 8.2 \\
\hline
\end{tabular}

${ }^{*} \mathrm{AIC}$, Akaike information criterion; AR, autoregressive; NAO, North Atlantic oscillation.

\section{About the Author}

Dr. Tkadlec is a professor of ecology in the Department of Ecology and Environmental Sciences at Palacký University Olomouc, Czech Republic. His research interests include population ecology of vertebrates.

\section{References}

1. Han BA, Schmidt JP, Bowden SE, Drake JM. Rodent reservoirs of future zoonotic diseases. Proc Natl Acad Sci U S A. 2015;112:7039-44. http://dx.doi.org/10.1073/pnas.1501598112

2. van Duijvendijk G, Sprong H, Takken W. Multi-trophic interactions driving the transmission cycle of Borrelia afzelii between Ixodes ricinus and rodents: a review. Parasit Vectors. 2015;8:643. http://dx.doi.org/10.1186/s13071-015-1257-8

3. Tkadlec E, Stenseth NC. A new geographical gradient in vole population dynamics. Proc Biol Sci. 2001;268:1547-52. http://dx.doi.org/10.1098/rspb.2001.1694

4. Krebs CJ. Population fluctuations in rodents. Chicago: University of Chicago Press; 2013.

5. Gilbert L, Maffey GL, Ramsay SL, Hester AJ. The effect of deer management on the abundance of Ixodes ricinus in Scotland. Ecol Appl. 2012;22:658-67. http://dx.doi.org/10.1890/11-0458.1

6. Cayol C, Koskela E, Mappes T, Siukkola A, Kallio ER. Temporal dynamics of the tick Ixodes ricinus in northern Europe: epidemiological implications. Parasit Vectors. 2017;10:166. http://dx.doi.org/10.1186/s13071-017-2112-x

7. Ostfeld RS, Schauber EM, Canham CD, Keesing F, Jones CG, Wolff JO. Effects of acorn production and mouse abundance on abundance and Borrelia burgdorferi infection prevalence of nymphal Ixodes scapularis ticks. Vector Borne Zoonotic Dis. 2001;1:55-63. http://dx.doi.org/10.1089/153036601750137688

8. Ostfeld RS, Levi T, Keesing F, Oggenfuss K, Canham CD. Tick-borne disease risk in a forest food web. Ecology. 2018; 99:1562-73. http://dx.doi.org/10.1002/ecy.2386

9. Sonenshine DE, Mather TN, editors. Ecological dynamics of tick-borne diseases. Oxford: Oxford University Press; 1994.

10. Keesing F, Brunner J, Duerr S, Killilea M, Logiudice K, Schmidt K, et al. Hosts as ecological traps for the vector of Lyme disease. Proc Biol Sci. 2009;276:3911-9. http://dx.doi.org/10.1098/ rspb.2009.1159

11. Šumilo D, Bormane A, Asokliene L, Vasilenko V, Golovljova I, Avsic-Zupanc T, et al. Socio-economic factors in the differential upsurge of tick-borne encephalitis in Central and Eastern Europe. Rev Med Virol. 2008;18:81-95. http://dx.doi.org/10.1002/rmv.566

12. Blaškovič $\mathrm{D}$. The public health importance of tick-borne encephalitis in Europe. Bull World Health Organ. 1967;36(Suppl):5-13.

13. Pelikán J. Stanoviště, sídlišš a etologie. In: Kratochvíl J, Balát F, Folk Č, Grulich I, Havlín J, Holišová V, et al., editors. Hraboš polní, Microtus arvalis. Prague: Nakladatelství ČSAV; 1959. p. 80-100.

14. Daniel M, Kříž B, Danielová V, Beneš Č. Sudden increase in the tick-borne encephalitis cases in the Czech Republic, 2006. Int J Med Microbiol. 2008;298(S1):81-7. http://dx.doi.org/10.1016/ j.ijmm.2008.02.006

15. Carslake D, Cornulier T, Inchausti P, Bretagnolle V. Spatio-temporal covariation in abundance between the cyclic common vole Microtus arvalis and other small mammal prey species. Ecography. 2011;34:327-35. http://dx.doi.org/10.1111/ j.1600-0587.2010.06334.x

Address for correspondence: Emil Tkadlec, Palacký University Olomouc, Department of Ecology and Environmental Sciences, Faculty of Science, Šlechtitelů 27, 78371 Olomouc, Czech Republic; e-mail: emil.tkadlec@upol.cz 